\title{
FAKTOR-FAKTOR PENENTU PEMBERIAN PEMBIAYAAN GRIYA BSM PADA PT.BANK SYARIAH MANDIRI KANTOR CABANG PADANG
}

\author{
Annisa Raihana, Elva Dona \\ Akademi Keuangan Dan Perbankan "Pembangunan" Padang" \\ annisa.raihana@gmail.com
}

\begin{abstract}
The purpose of the study was to find out what factors were the determinants of providing BSM salary financing at the stage of applying for financing to the disbursement stage using the $5 C+1 S$ principles, namely character, capacity, capital, collateral, conditions and Sharia so that non-performing financing occurs in the future future. The results of this research are what factors differentiate the provision of financing to Islamic banks with conventional banks.
\end{abstract}

Keywords : BSM Griya Financing, 5C Principles and Sharia Principles in Bank Syariah Mandiri

\section{PENDAHULUAN}

Bank syariah merupakan lembaga keuangan yang dijalankan atas prinsip syariah Islam, dimana kegiatan usahanya bank syariah berpedoman kepada AlQur'an dan Hadist, bank syariah lebih mengedepankan sistem bagi hasil, sewa, dan jual beli bukan menggunakan sistem bunga hal tersebut yang membedakan sama bank konvensional yang mengunakan sistem bunga. Menurut UndangUndang No. 21 Tahun 2008, Pasal 1, Bank Syariah merupakan bank yang aktivitasnya berdasarkan Prinsip Syriah berdasarkan bentuk terdiri dari Bank Umum Syariah dan Pembiayaan Rakyat Syariah.

Di Indonesia sistem perbankan yang digunakan ialah dual banking dimana beroperasi dua jenis usaha bank yaitu Bank Syariah dan Bank Konvensional. Di Bank Syariah tidak memakai sistem bunga, maka keuntungan yang didapat berasal dari bagi hasil dari kegiatan yang memanfaatkan dana Bank Syariah dan penanaman modal pada Bank Syariah itu sendiri (Qolby, 2013).

Bank Syariah merupakan lembaga keuangan yang mengumpulkan simpanan dari masyarakat dan mengalirkan kepada masyarakat menurut pedoman syariah Islam yaitu Al-Qur'an dan Hadist (Nasir \& Sululing, 2015). Bank syariah yang ada di Indonesia salah satunya adalah Bank Syariah Mandiri.

Pada umumnya, produk-produk yang diberi oleh perbankan syariah terdiri dari tiga bagian yaitu : produk pembiayaan (financing), produk penghimpunan dana (funding), dan produk jasa (service) (Heykal, 2014). 
PT. Bank Syariah Mandiri Kantor Cabang Padang memiliki beraneka macam produk pembiayaan salah satu produk pembiayaan yang ada di bank tersebut ialah Pembiayaan Griya BSM. Pembiayaan ini dijadikan sebagai salah satu pilihan guna mewujudkan impian nasabah untuk memiliki rumah hunian yang nyaman.

Pembiayaan Griya BSM merupakan pembiayaan jangka pendek, menengah, atau panjang untuk memodali pembelian rumah tinggal baik baru maupun bekas, di wilayah developer atau non developer memakai aturan akad murabahah (Turmudi, 2015).

Bank Syariah Mandiri saat mengeluarkan pembiayaan griya kinerja keuangan haruslah bagus sehingga fungsinya berjalan lancar. Menurut (Azmi, 2015) faktor-faktor yang menentu pembiayaan griya BSM yaitu mengunakan prinsip $5 \mathrm{C}+1 \mathrm{~S}$, yang mana $5 \mathrm{C}$ tersebut terdiri dari character, capital, capacity, collateral, condition, dan syariah. Yang membedakan Bank Syariah sana Bank Konvensional dalam pemberian pembiayaan Bank Syariah menggunakan prinsip syariah yang di keluarkan oleh Dewan Syariah Nasional yang mana prinsip syariah dalam pemberian pembiayaan pada Bank Syariah Mandiri ialah Bank harus memperhatikan tujuan nasabah melakukan permohonan pembiayaan haruslah sama dengan syariat Islam.

Berdasarkan gambaran diatas, maka penulis ingin mengajukan dalam bentuk tugas akhir dengan judul "Faktor-Faktor Penentu Pemberian Pembiayaan Griya Bsm Pada Pt. Bank Syariah Mandiri Kantor Cabang Padang”.

Berdasarkan penjelasan latar belakang diatas, lalu rumusan masalah pada penelitian ini adalah "apa saja faktor-faktor penentu pemberian pembiayaan griya BSM pada PT. Bank Syariah Mandiri Kantor Cabang Padang?”. Penelitian ini bertujuan guna mengetahui faktor-faktor penentu pemberian pembiayaan griya BSM pada PT. Bank Syariah Mandiri Kantor Cabang Padang. Adapun manfaat penelitian ini, penulis berharap penelitian ini bisa bermanfaat baik bagi penulis, perusahaan maupun perguruan tinggi, manfaatnya yaitu : a. Bagi Penulis, penelitian ini mampu meningkatkan pemahaman, memperluas pandangan penulis terhadap permasalahan yang diteliti, dan sebagai salah satu syarat untuk memenuhi persyaratan memperoleh derajat sarjana D3 program studi keuangan dan perbankan AKBP Padang. b. Bagi Perusahaan, sebagai standar bagi PT. Bank Syariah Mandiri Kantor Cabang Padang untuk menilai apakah bank sudah melakukan berdasarkan aturan yang telah ditetapkan, dan sebagai acuan dimasa yang akan datang. c. Bagi Akademian, diharapkan hasil penelitian ini khususnya dibidang keuangan dan perbankan dapat menambah referensi, informasi, dan wawasan untuk penelitian lebih lanjut yang khususnya berhubungan dengan pembiayaan.

\section{METODE PENELITIAN}

Dalam pengumpulan data dan bahan untuk penelitian ini digunakan metode penelitian sebagai berikut: a. Metode Pengumpulan Data, 1) Studi Lapangan (Field Research) Peninjauan langsung ke tempat penelitian yang dipilih untuk meneliti hasil data primer. Penelitian langsung kelapangan ini akan dapat membantu penulis untuk melengkapi data yang diperlukan. Adapun cara riset 
lapangan ini adalah dengan mewawancarai langsung pihak yang bersangkutan yaitu perusahaan dan instansi yang terkait. 2) Studi Perpustakaan (Library Research), Penelitian ini dilakukan ke perpustakaan dengan membaca buku-buku tentang faktor-faktor penentu pemberian pembiayaan pada suatu bank dan bacaan yang berkaitan dengan pembahasan yang dilakukan. b. Metode Analisis Data, Metode analisis data yang digunakan ialah data deskriptif yaitu menggambarkan, memahami, dan menjelaskan data yang berhubungan dengan masalah yang diambil pada penelitian.

\section{ANALISIS DAN PEMBAHASAN}

\section{Faktor-Faktor Penentu Pemberian Pembiayaan Griya BSM}

Pembiayaan griya BSM di pengaruhi oleh beberapa faktor berdasarkan prinsip 5C $+1 \mathrm{~S}$ diantaranya sebagai berikut :

a. Character, yaitu penilaiannya terhadap kepribadian calon pemohon serta melihat langsung ke daerah tempat tinggal pemohon sehingga bank dapat memprediksi kemungkinan bahwa pemohon mampu membayar utangnya. Ada beberapa upaya yang dapat ditembus agar bank dapat mengetahui watak dari pemohon yaitu : bank memeriksa riwayat hidup calon nasabah, bank melihat bagaimana hubungan nasabah dengan tetangga dan teman kerjanya, memeriksa Sistem Informasi Debitur, mencari informasi calon nasabah suka brjudi atau tidak.

b. Capacity, yaitu melihat batas kesanggupan calon penerima pembiayaan untuk melakukan pelunasan pembiayaan tersebut. Kesanggupan calon nasabah diperhatikan dari laporan keuangan seperti laporan laba atau rugi nasabah. Ada beberapa strategi yang mampu mengukur kemampuan calon nasabah, yaitu : pendekatan historis, usaha yang dimiliki nasabah menampilkan perkembangan dari tahun ketahun atau tidak, pendekatan finansial yaitu dengan cara melihat asal usul pendidikan nasabah, pendekatan yuridis yaitu pendekatan dimana melihat nasabah memiliki kapasitas atau tidak untuk melakukan kerja sama, pendekatan manajerial yaitu dengan cara menilai kemampuan dan ketrampilan calon nasabah dalam mengerjakan usahanya, pendekatan teknis yaitu mengukur keahlian dan ketrampilan calon nasabah saat mengatur usahanya seperti strategi nasabah dalam memajukan usahanya serta karyawan yang dimiliki.

c. Capital, yaitu penyediaan terhadap prinsip permodalan debitur tidak hanya melihat besar kecilnya aset tersebut, tapi juga penyaluran modal itu ditempatkan oleh debitur. Cukupkah modal yang tersedia sehingga segala sumber mampu beroperasi secara sehat. Baik pengaturan modal itu sehingga perusahaan berjalan lancar. Berapa besar modal kerjanya semua ini dapat dilihat dari kondisi neraca perusahaan calon debitur.

d. Collateral,yaitu penilaian terhadap jaminan nasabah sebagai jaminan atas pinjaman yang diterima. Nilai jaminan tersebut diharapkan 
dapat merahasiakan apabila terjadi masalah sebelum masa pelunasan selesai. Setelah itu, manfaat dari jaminan tersebut adalah sebagai alat pengaman terhadap kemungkinan tidak mampunya nasabah melunasi pembiayaan yang ia terima.

e. Condition, yaitu bank syariah harus melihat status ekonomi di masyarakat yang dapat mempengaruhi perkembangan usaha nasabah. Selain itu, bank juga mnelihat kemampuan nasabah dalam memajukan usahanya. Alasan bank melihat kondisi di lingkungan usaha nasabah adalah agar bank dapat menilai kemampuan nasabah dalam melunasi kewajibannya.

f. Syariah, yaitu penilaian atas tujuan pembiayaan ini dilakukan agar tidak terjadi transaksi yang cacat dikarenakan objek pembiayaannya tidak sesuai syariat Islam seperti sebagai tempat untuk penjualan miras dan lain sebagainya.

\section{Pembiayaan Griya BSM}

Dimana pembiayaan Griya BSM pada Bank Syariah Mandiri memiliki keunggulan sebagai berikut : Anggaran tetap sampai jatuh tempo pembiayaan,proses permohonan yang mudah dan cepat, fleksibel untuk membeli rumah baru maupun second. Dan syarat-syarat pembiayaan griya BSM sebagai berikut : WNI yang tau akan hukum, usia dari 21 tahun sampai 55 tahun pada waktu jatuh tempo pembiayaan, maksimum pembiayaan, maksimum pembiayaan griya BSM terdapat pada tabel 1 berikut :

\section{Tabel 1}

Maksimum pembiayaan pada PT. Bank Syariah Mandiri

\begin{tabular}{|l|c|c|c|}
\hline \multirow{2}{*}{$\begin{array}{c}\text { Pembiayaan dan } \\
\text { Tipe Agungan }\end{array}$} & \multicolumn{3}{|c|}{ FTV Maksimum } \\
\cline { 2 - 4 } & $\begin{array}{c}\text { FP1 } \\
\text { (Pertama) }\end{array}$ & $\begin{array}{c}\text { FP2 } \\
\text { (Kedua) }\end{array}$ & $\begin{array}{c}\text { FP3 } \\
\text { (Ketiga) }\end{array}$ \\
\hline PPR Tipe >70 & $70 \%$ & $60 \%$ & $50 \%$ \\
\hline PPRS Tipe $>70$ & $70 \%$ & $60 \%$ & $50 \%$ \\
\hline PPR Tipe 22 -70 & Tidak Diatur & $70 \%$ & $60 \%$ \\
\hline PPRS Tipe 22 -70 & $80 \%$ & $70 \%$ & $60 \%$ \\
\hline PPRS Tipe s/d 21 & Tidak Diatur & $70 \%$ & $60 \%$ \\
\hline Ruko/Rukan & Tidak Diatur & $70 \%$ & $60 \%$ \\
\hline
\end{tabular}

Sumber : Bank Syariah Mandiri

Keterangan :

a) FTV = Financing to Value, FP = Fasilitas Pembiayaan, FP $1=$ Fasilitas Pembiayaan untuk rumah pertama, dan seterusnya, PPRS = Pembiayaan Pemilikan Rumah Susun

b) Besar angsuran tidak melebihi $40 \%$ dari penghasilan bulanan bersih, fasilitas pembiayaan untuk unit yang belum selesai dibangun/inden dapat diberikan untuk fasilitas pembiayaan yang pertama, pencairan pembiayaan dapat diberikan apabila progres pembangunan telah mencapai 50\%, dengan total pencairan maksimal sebesar $50 \%$, untuk pencairan unit yang belum selesai dibangun, harus melalui perjanjian antara developer dan BSM Kantor Pusat. Dari data Bank 
Syariah Mandiri pembiayaan griya BSM per Maret 2017 berjumlah 9,27 triliun dengan jumlah nasabah 44 ribu.

Dokumen yang diperlukan : Foto copy KTP pemohon, foto copy Kartu Keluarga, foto copy surat nikah (bila sudah menikah)asli slip gaji dan surat keterangan kerja, foto copy Rekening Koran 3 bulan terakhir, foto copy NPWP untuk pembiayaan di atas Rp.50 juta, foto copy rekening telepon dan listrik, foto copy Surat Hak Milik atau Sertifikat Hak Guna Bangunan, foto copy Izin Mendirikan Bangunan dan Denah Bangunan, surat pernyataan nasabah mengenai fasilitas pembiayaan yang telah diterima maupun yang sedang dalam proses pengajuan permohonan di Bank Syariah Mandiri maupun pada Bank lain.

Permohonan pinjaman dinyatakan lengkap apabila telah memenuhi persyaratan yang telah ditentukan bank untuk mengajukan permohonan. Apabila persyaratan belum terpenuhi, atau masih dalam proses, maka berkasberkas tersebut harus disimpan ke dalam berkas permohonan.

\section{Mekanisme Pembiayaan Griya BSM}

a. Tahap permohonan dan pengajuan persyaratan

Nasabah datang ke bank untuk mengajukan keinginannya dalam memperoleh pembiayaan untuk pembelian suatu bidang tanah, serta bangunan rumah yang terdapat di atasnya baik dari developer maupun perorangan atau pembiayaan untuk merenovasi rumah. Adapun tahap pengajuan permohonan sebagai berikut : Petugas bank mewawancarai nasabah secara umum, mengenai objek dan keperluan pembiayaan serta hal-hal yang bersangkutan dengan usaha, setelah itu bank memberikan formulir permohonan pembiayaan yang diisi oleh nasabah beserta persyaratan pembiayaan yang harus dipenuhi nasabah seperti pada tabel 2 berikut :

Tabel 2

Dokumen yang dibutuhkan dalam Permohonan Pembiayaan

\begin{tabular}{|l|l|r|r|r|}
\hline No & Jenis Dokumen & PG & WS & PO \\
\hline 1 & $\begin{array}{l}\text { Asli formulir permohonan pembiayaan } \\
\text { yang telah diisi lengkap dan di } \\
\text { tandatangani }\end{array}$ & $\checkmark$ & $\checkmark$ & $\checkmark$ \\
\hline 2 & Foto copy KTP (nasabah dan pasangan) & $\checkmark$ & $\checkmark$ & $\checkmark$ \\
\hline 3 & Foto copy Kartu Keluarga & $\checkmark$ & $\checkmark$ & $\checkmark$ \\
\hline 4 & Foto copy akte nikah/cerai & $\checkmark$ & $\checkmark$ & $\checkmark$ \\
\hline 5 & $\begin{array}{l}\text { Asli slip gaji/surat ketrangan penghasilan } \\
\text { terakhir }\end{array}$ & $\checkmark$ & & \\
\hline 6 & $\begin{array}{l}\text { Foto copy surat keputusan pengangkatan } \\
\text { pegawai tetap }\end{array}$ & $\checkmark$ & & \\
\hline 7 & $\begin{array}{l}\text { Foto copy rekening tabungan/koran (3 } \\
\text { bulan terakhir) }\end{array}$ & $\checkmark$ & $\checkmark$ & $\checkmark$ \\
\hline 8 & Surat persetujuan suami/istri & $\checkmark$ & $\checkmark$ & $\checkmark$ \\
\hline 9 & $\begin{array}{l}\text { Foto copy NPWP (untuk jumlah } \\
\text { pembiayaan >Rp. 50 juta) }\end{array}$ & $\checkmark$ & $\checkmark$ & $\checkmark$ \\
\hline 10 & Foto copy SSP dan SPT tahun terakhir & & $\checkmark$ & $\checkmark$ \\
\hline
\end{tabular}




\begin{tabular}{|c|c|c|c|}
\hline 11 & Foto copy izin usaha atau izin praktek & $\checkmark$ & $\checkmark$ \\
\hline 12 & $\begin{array}{l}\text { Foto copy laporan keuangan dua tahun } \\
\text { terakhir }\end{array}$ & $\checkmark$ & \\
\hline 13 & $\begin{array}{l}\text { Foto copy KTP direksi dan komisaris atau } \\
\text { pengurus dan pengawas }\end{array}$ & $\checkmark$ & \\
\hline
\end{tabular}

Sumber : Surat Edaran Pembiayaan Griya

Keterangan :

1) $\mathrm{PG}=$ Pegawai tetap, $\mathrm{WS}=$ Wiraswasta, $\mathrm{PO}=$ Profesional

2) Bank melakukan verifikasi keaslian dokumen diatas terdapat stempel "copy sesuai asli", tanggal verifikasi dan paraf petugas.

Tabel 3

Dokumen Agunan yang dibutuhkan dalam permohonan pembiayaan

\begin{tabular}{|l|c|c|c|}
\hline \multicolumn{1}{|c|}{ Dokumen Aguanan } & R. Baru & $\begin{array}{l}\text { R. } \\
\text { Bekas }\end{array}$ & Renovasi \\
\hline $\begin{array}{l}\text { Foto copy SHM (surat hak milik) SHGB } \\
\text { (surat hak guna bangunan) dan IMB (izin } \\
\text { mendirikan bangunan) }\end{array}$ & $\checkmark$ & $\checkmark$ & $\checkmark$ \\
\hline $\begin{array}{l}\text { Foto copy PBB (pajak bumi dan } \\
\text { bangunan) 2 tahun terakhir }\end{array}$ & & $\checkmark$ & $\checkmark$ \\
\hline $\begin{array}{l}\text { Rencana anggaran biaya (RAB) atas } \\
\text { rumah untuk pembangunan/renovasi }\end{array}$ & $\checkmark$ & $\checkmark$ & $\checkmark$ \\
\hline $\begin{array}{l}\text { Price Listdari developer atau surat } \\
\text { penawaran dari penjualan perorangan }\end{array}$ & $\checkmark$ & $\checkmark$ & $\checkmark$ \\
\hline Sketsa jalan/peta menuju lokasi & $\checkmark$ & $\checkmark$ & $\checkmark$ \\
\hline
\end{tabular}

Sumber : Surat Edaran Pembiayaan Griya

b. Tahapan pemeriksaan dan analisis oleh bank

Pada tahap ini bank memverifikasi kelengkapan dokumen nasabah, dan pemeriksaan kelapangan mengenai target yang akan dibiayai, jaminan yang diberikan nasabah, keadaan usaha/pekerjaan nasabah dan verifikasi data yang disampaikan nasabah dengan kondisi lapangan, selanjutnya bank menganalisa kelayakan nasabah dengan metode 5C, yaitu character, capacity, capital, condition of economy, collateral.

c. Tahap persetujuan komite

Setelah melalui proses pemeriksaan dan analisis, kemudian berkas permohonan nasabah beserta hasil pemeriksaan dan analisa disampaikan kepada komite pembiayaan yang terdiri dari kepala cabang. Untuk pinjaman sebesar Rp. 500 juta - Rp. 5M diteruskan dan diputuskan oleh kepala pusat PT. Bank Syariah Mandiri.

Keputusan atas permohonan pembiayaan dapat berupa persetujuan atau penolakan, yang akan dibuatkan dalam suatu surat keputusan komite pembiayaan (SKKP) yamg akan disampaikan kepada nasabah. Untuk permohonan pembiayaan yang diterima, dibuatkan kembali surat penegasan persetujuan pembiayaan (SP3), SP3 tidak terpisahkan dari akad perjanjian pinjaman yang akan dibuat dan ditandatangani oleh nasabah dan bank. 
d. Tahap penandatanganan akad harus memenuhi persyaratan sebagai berikut: Nasabah telah menyerahkan surat penegasan persetujuan pembiayaan (SP3) yang telah ditandatangani di atas materai Rp. 6.000, nasabah telah menyerahkan dokumen-dokumen pembiayaan sesuai aturan yang berlaku di PT. BSM Kantor Area Padang,menyerahkan asli bukti kepemilikan jaminan kepada PT. BSM Kantor Cabang Padang beserta dokumen terkait lainnya, untuk selanjutnya dilakukan pengikatan jaminan secara notarial.

Tabel 4

Jenis Jaminan Dalam Pembiayaan Griya

\begin{tabular}{|c|c|c|c|}
\hline No & Jenis Jaminan & Keterangan & Contoh \\
\hline 1 & Jaminan Utama & $\begin{array}{l}\text { Objek } \\
\text { pembiayaan }\end{array}$ & $\begin{array}{l}\text { Rumah yang dibiayai } \\
\text { bank }\end{array}$ \\
\hline 2 & $\begin{array}{l}\text { Jaminan } \\
\text { tambahan }\end{array}$ & $\begin{array}{l}\text { Jaminan ini } \\
\text { wajib } \\
\text { diserahkan oleh } \\
\text { nasabah apabila } \\
\text { bank menilai } \\
\text { adanya kerugian }\end{array}$ & $\begin{array}{ll}1 & \text { Rumah (tanah dan } \\
& \text { bangunan). } \\
2 & \text { Rumah toko } \\
3 & \text { Kendaraan } \\
4 & \text { Cash colleteral } \\
& \text { (dana tunai) }\end{array}$ \\
\hline
\end{tabular}

Sumber : surat Edaran Pembiayaan Griya, 2011

Jaminan yang berupa tanah atau bangunan harus diikat secara APHT (akta pembebanan hak tanggung). Sedangkan jaminan yang berupa kendaraan yang harus diikat secara fidusia oleh notaris dan wajib didaftarkan ke lembaga pendaftaran fidusia. Jaminan yang berupa cash collateral, dana disimpan dalam bentuk tabungan/giro/deposito. Pengikatan jaminan dilakukan sewaktu pembiayaan .

Pengikatan semua jaminan dilakukan oleh notaris, dan notaris wajib menyerahkan covernote, bahwa:Proses pengikatan jaminan paling lambat selesai dalam jangka waktu 90 hari kalender, dokumen legal objek jaminan dan dokumen pengikatan jaminan akan diserahkan secara langsung kepada bank sesuai waktu.

e. Membuka rekening dan menyiapkan dana untuk membayar biaya-biaya yang dikeluarkan atas pembiayaan tersebut. Biya-biaya yang dapat dibebenkan kepada nasabah (sesuai kondisi) adalah : biaya administrasi pembiayaan sesuai ketentuan di bank, biaya asuransi kerugian terhadap objek pembiayaan dan objek jaminan yang bukan objek pembiayaan, biaya asuransi jiwa. biaya jasa notaris, telah menyerahkan surat kuasa untuk melakukan pendebetan rekening atas transaksi yang berhubungan dengan fasilitas pembiayaan seperti biaya-biaya yang dikeluarkan dan pembayaran angsuran perbulan. Setelah persyaratan dipenuhi, dilakukan pendatanganan akad antara nasabah dan bank. Akad yang ditandatangani yaitu akad murabahah dan akad wakalah. Akad murabahah adalah untuk objek pembiayaan griya. Sedangkan akad wakalah adalah akad yang digunakan untuk memberi kuasa oleh bank kepada nasabah untuk memberi kuasa 
oleh bank kepada nasabah untuk membelikan barang yang dimaksud pada akad pembiayaan griya.

f. Tahapan pencairan

Setelah persyaratan dipenuhi dan akad telah dilakukan, pencairan dana dapat dilakukan, dan bank akan memberikan dana pembelian rumah, selanjutnya nasabah akan menandatangani tanda bukti penerimaan uang, sebagai bukti telah diterimanya dana oleh nasabah dari bank.Bank akan membayarkan pembelian rumah yang dimaksud ke rekening penjual/pemasok melalui rekening nasabah yang ada pada bank. Dan nasabah menerima faktur/invoice, kwitansi/tanda pembayaran lainnya dari penjualan/pemasok sebagai bukti telah dilakukannya pembelian rumah untuk kemudian diserahkan kepada bank sebagai tanda terima barang oleh nasabah.

\section{g. Tahapan monitoring}

Setelah semua tahapan dilakukan dan dipenuhi maka proses yang terakhir dari pembiayaan adalah proses monitoring atau proses mengawasi. Bagi officer bank syariah, pada saat menempuh tahap ini maka sebenarnya risiko pembiayaan baru saja dimulai saat pencairan dilakukan. Proses mengawasi dapat dilakukan dengan mengawsi realisasi pencapaian target usaha menggunakan bisiness plan yang telah dibuat sebelumnya.

Apabila terjadi tidak tercapainya target, maka officer bank harus segera mengerjakan tindakan seperti survei nasabah agar mengetahui permasalahan yang dialami nasabah, kemudian memberikan solusi kepada nasabah. Beberapa langkah monitoring yang harus dilakukan antara lain : mengawasi perpindahan rekening koran nasabah, mengawasi pelunasan angsuran, melakukan kunjungan rutin ke tempat usaha nasabah untuk memantau langsung operasional usaha dan pertumbuhan usaha, melakukan pengamatan terhadap pertumbuhan usaha serupa melalui media masa atau media lainnya. Dalam memberikan pembiayaan, bank wajib mempunyai kepercayaan berdasarkan analisis yang mendalam atas kemampuan nasabah debitur untuk melaksanakn kewajibannya yaitu menyelesaikan pembiayaan sesuai dengan perjanjian. Semua tahapan yang dilakukan oleh bank tersebut adalah upaya dalam mengantisipasi hal-hal yang tidak diinginkan terjadi di kemudian hari.

\section{SIMPULAN}

Penyusunan Tugas Akhir ini dimaksudkan agar mengetahui faktor penentu pemberian pembiayaan griya BSM menggunakan prinsip $5 \mathrm{C}+1 \mathrm{~S}$ pada pembiayaan griya BSM. Di dalam penelitian yang dilakukan peneliti hanya terdapat satu objek penelitian yaitu PT. Bank Syariah Mandiri Kantor Cabang Padang. Berdasarkan hasil wawancara yang dilakukan oleh peneliti, maka peneliti dapat menarik kesimpulan sebagai berikut :

1. Bank Syariah Mandiri Kantor Cabang Padang memiliki beberapa produk pembiayaan, dibuat menjadi dua jenis yaitu :

a. Pembiayaan konsumer 
Beberapa produk dari pembiayaan konsumer yaitu BSM Implan, Pembiayaan Peralatan Kedokteran, Pembiayaan Edukasi BSM, Pembiayaan Griya BSM, Pembiayaan Pemilikan Mobil atau Kendaraan, Pembiayaan Pemilikan Rumah atau Pembiayaan Griya BSM Bersubsidi, Gadai emas di BSM

b. Pembiayaan Modal Kerja

Beberapa produk dari pembiayaan modal kerja yaitu BSM Customer Network Financing (BSM-CNF), Pembiayaan Warung Mikro, Pembiayaan Business Banking. Dari banyaknya produk dan jenis pembiayaan, masyarakat lebih memilih pembiayaan konsumer karena dari sisi kebutuhan masyarakat, pembiayaan konsumer sangat cocok dan membantu bagi nasabah yang membutuhkan pembiayaan.

2. Faktor penentu pemberian pembiayaan pada PT. Bank Syariah Mandiri Kantor Cabang Padang telah dilakukan sesuai SOP (Standar Operasional dan Prosedur) Pembiayaan yang sudah ditentukan. Didalam melaksanakan tahapan pembiayaan bank mempunyai prosedur sebagai berikut, pengajuan permohonan pembiayaan, penyelidikan pembiayaan, wawancara, peninjauan langsung ke lokasi pemohon, wawancara kedua, keputusan pembiayaan, penandatanganan akad, dan selanjutnya penyerahan objek pembiayaan pada nasabah.

3. Saat melakukan analisis kelayakan calon nasabah, Bank Syariah Mandiri Kantor Cabang Padang memakai prinsip 5C+1S dalam pembiayaan, hal ini untuk menentukan pengajuan pembiayaan yang diajukan disetujui atau ditolak. Di BSM Kantor Cabang Padang prinsip 5C+1S saling berkaitan dan saling melengkapi, sehingga tidak ada yang diprioritaskan. Akan tetapi ada sejumlah langkah bank sebelum bank menganalisis lebih lanjut. Dari tahapan $5 \mathrm{C}+1 \mathrm{~S}$ dilakukan secara berurutan agar analisis dilakukan efektif dan tidak sia-sia.

\section{UCAPAN TERIMAKASIH}

Terimakasih penulis ucapkan kepada:

1. Kedua orang tua yang senantiasa memberikan dukungan baik secara moril maupun materil.

2. Direktur AKBP beserta prodi AKBP yang telah memberikan kesempatan kepada penulis untuk melakukan penelitian ini.

3. Dosen pembimbing yang telah memberikan arahan dan bimbingan hingga tugas akhir ini bisa terselesaikan.

4. Branch manager PT. Bank Syariah Mandiri Kantor Cabang Padang yang telah mengizinkan penulis dalam memperoleh informasi beserta pengambilan data.

5. Semua pihak yang telah memberikan dukungan dan bantuannya dalam penyelesaian tugas akhir ini. 


\section{DAFTAR PUSTAKA}

Alanshari, F., \& Marlius, D. (2018). Prosedur Pemberian Kredit KPR Pada PT. Bank Tabungan Negara (Persero) TBK Cabang Pembantu Bukittinggi. https://doi.org/10.31227/osf.io/rsfhc

Andriani, B., \& Susanto, R. (2019). Pengawasan Kredit PT. Bank Perkreditan Rakyat (BPR) Ophir Pasaman Barat. https://doi.org/10.31219/osf.io/aunvc

Amelia, L., \& Marlius, D. (2018). Pengendalian Kredit Dalam Upaya Menciptakan Bank Yang Sehat Pada PT. Bank Pembangunan Daerah Sumatera Barat Cabang Utama Padang. https://doi.org/10.31227/osf.io/kpc64 Azmi, F. (2015). Faktor Internal Dan Eksternal Yang Mempengaruhi Pembiayaan Murabahah Pada Perbankan Syariah Di Indonsia. Graduasi, 34(1), 53-70.

Baiya, \& Fernos, J. (2019). Analisis Faktor-Faktor Penyebab Kredit Macet Pada Bank Nagari Cabang Siteba. https://doi.org/10.31227/osf.io/4xuks

Darmawanto, \& Fernos, J. (2019). Prosedur Pemberian Kredit Pada Bank Nagari Cabang Sijunjung. https://doi.org/10.31227/osf.io/psqfy

Firmansyah, A., \& Fernos, J. (2019). Analisis Kredit Bermasalah Dilihat Dari Standar Non Performing Loan (NPL) Pada PT. Bank Perkreditan Rakyat (BPR) Prima Mulia Anugrah Cabang Padang. https://doi.org/10.31227/osf.io/gcj94

Heykal, M. (2014). Analisis Tingkat Pemahaman Kpr Syariah Pada Bank Syariah Di Indonesia : Studi Pendahuluan. Binus Business Review, 5(2), 519-526.

Nasir, M. S., \& Sululing, S. (2015). Penerapan Akuntansi Murabahah Terhadap Pembiayaan Kredit Pemilikan Rumah Pada Bank Syariah Mandiri Cabang Luwuk. Akuntansi, XIX(01), 109-128.

Qolby, L. M. (2013). Faktor - Faktor Yang Mempengaruhi Pembiayaan Pada Perbankan Syariah Di Indonesia Periode Tahun 2007 - 2013. Economics Development Analysis, 2(4), 367-383.

Turmudi, M. (2015). Pembiayaan Griya Bank Syari'ah Mandiri (Studi Kasus Bank Syari'ah Mandiri Cabang Kendari). Al-Izzah, 10(1), 89-106.

Widayati, R. (2019). Penyelesaian Kredit Bermasalah Pada PT. Bank Perkreditan Rakyat (BPR) Nagari Kasang. https://doi.org/10.17605/OSF.IO/D4MF3

Widayati, R. (2019). Pelaksanaan Prinsip Kehati-Hatian Dalam Pemberian Kredit Konsumtif Pada Bank Nagari Cabang Siteba. https://doi.org/10.17605/OSF.IO/FZVXR

Widayati, R. (2019). Aktivitas Pemberian Kredit Komersil Pada Bank Nagari Cabang Sijunjung. https://doi.org/10.17605/OSF.IO/QTVZ9

Widayati, R. (2019). Pelaksanaan Kredit Pada Bank Perkreditan Rakyat LPN Pasar Baru Durian Sawahlunto. https://doi.org/10.17605/OSF.IO/5HPAB

Widayati, R. (2019). Upaya Penanganan Kredit Bermasalah Pada Bank Nagari Cabang Utama Padang. https://doi.org/10.17605/OSF.IO/YJ3KN

Widayati, R. (2019). Aktivitas Pemberian Kredit Usaha Pada PT. Bank Perkreditan Rakyat Batang Kapas. https://doi.org/10.17605/OSF.IO/EDPN4 